\title{
The need of improvement of transport conditions in large Romanian cities
}

\author{
V. Rădulescu, I. Străinescu, L. Moroianu, C. Goia, E. Tudor, \\ F. Bozaş, V. Lupu, B. Rădulescu \& M. Tănase \\ Department R\&D of ICPE SAERP, Bucharest, Romania
}

\begin{abstract}
The development of the large cities in Romania, especially of the capital, Bucharest, and the exaggerated increase of the number of cars, mostly used cars from Western Europe with a long mileage, has contributed to the pollution of these cities and resulted in a horrific urban traffic, particularly during the morning and the evening rush hours.

To provide this kind of transportation in Bucharest and the surrounding areas, RATB uses $300 \mathrm{~km}$ of tram lines with a park of 500 tram wagons, 18 trolley lines with a $485 \mathrm{~km}$ network and a park of 300 trolleys, the bus transport system with a $2900 \mathrm{~km}$ network and a park of 1300 buses, 3 Light Rail (LR) lines and 4 subway lines..

This paper will examine the decision factors and the planning concerns to provide better conditions for urban transport in Bucharest and in the other large cities in Romania, especially with urban electrical vehicles.

Although the fleet of urban transport vehicles is based on electrical vehicles, because of the traffic jams during the rush hour, the satisfaction of the passengers is low (except for the light-rail and metro passengers). A lot of car owners are using car transport (even single occupancy) to the work place and shopping areas, resulting in terrible traffic. This is the reason why the light-rail transportation was developed in Bucharest and in major cities in Romania, as presented before.

In order to encourage the use of the urban transportation means (especially the electrical ones), we have proposed some measures to improve the comfort provided by urban public transport vehicles. The company ICPE SAERP Bucharest, that specializes in the production of electrical traction drives and auxiliary converters, is developing and continuously improving the equipment
\end{abstract}


and services concerning: auxiliary services equipment, climate converters for air conditioning systems, access to traffic information, quality of transport, the GPS position of the vehicle, easy payment of the transport fare, a common card for the surface transport (trams, trolleybuses and buses) and underground transport, easy access to vehicles, safety, security and cleanliness.

Keywords: modern transit, trams, trolleybuses, light metro, subway lines, capacity, travel time, light rail.

\section{Introduction}

To ensure this kind of transportation in Bucharest and the surroundings [1], RATB uses a network of:

- $60 \mathrm{~km}$ with 3 Light Rail (LR),

- $\quad 300 \mathrm{~km}$ tramcar lines with a park of almost 500 tramcars,

- $\quad 18$ trolley bus lines with a park of 300 trolley buses and

- a bus park of 1300 .

The transportation lines in Bucharest depend also on the 4 subway lines (a $5^{\text {th }}$ was started in 2012) so that the transportation is improved.

To design the urban electrical transport mode in Bucharest, a few criteria were taken into consideration: the system capacity, travel time, comfort/accessibility, on-time performance and most importantly the investment amount, depending on the particularity of the transport in the large cities in Romania, especially Bucharest.

Concerning the comfort/accessibility issue, these attributes refer to the relative comfort of passengers. These attributes include stop and vehicle amenities (controlled temperature inside vehicle, transport quality, type of seating, access to information, easiness of fare payment, access, security, cleanliness, etc) [2].

The paper strongly recommends the extension of the light metro lines (LM) in Bucharest, using part of the existing tram tracks, modernizing the track and station infrastructure, blocking the automobile access to the LM tracks, by modernizing the traffic lights and introducing automatic barriers and electrical frames with hierarchical command on at least three levels.

All of this implies large investments distributed over long time periods and subsidies from the city halls that should cover the exploitation costs after renouncing of most of the diesel buses and powerful expansion of non-polluting electrical transportation.

According to the MASTER PLAN PMB, elaborated by the Bucharest City hall for the 2008-2027 period, the capacity of urban transportation network will increase.

The improvement of the public transportation will be done not only by introducing new routes/lines, but also by improving the performances of existing networks and also by implementing intelligent traffic management systems [3].

As we have learned from previous papers [3], although in Bucharest and other cities in Romania many measures to improve the urban traffic (especially during rush hours 8-11 am, respectively 5-8 pm) have been implemented, many car 
owners still use their vehicles even if they are the sole occupant. The reasons vary: some people have got used to using their car and prefer it instead of public transportation; others complain because of the lack of comfort (the metro can be quite a challenge when the weather conditions are harsh i.e. rain, snow; the metro frames run at intervals of 8-10 min, but they're technically designed to operate at 2 min between frames); another reason might be the lack of a universal fare system for ground and underground transportation.

This paper presents the implemented and proposed measures by ICPE SAERP to improve comfort on urban electrical vehicles in Bucharest and other large cities in Romania.

\section{Static converter for the auxiliary services and air conditioner for urban electrical vehicles}

To ensure the auxiliary services on tramcars in use in Romania, over 250 type CS12TB static converters have been delivered. These are supplied by rated voltages of $750 \mathrm{Vdc}$ or $600 \mathrm{Vdc}$ and ensure a rated output current of $120 \mathrm{~A}$. This current is used for the $24 \mathrm{Vdc}$ auxiliary services consumers and to supply the emergency brake during braking, making it safer and more silent.

To attract more passengers for urban transportation vehicles (especially the electrical kind), ICPE SAERP's proposal was accepted by city hall representatives, implying the installation of the air conditioning systems on the new vehicles (for both cooling and heating). This measure ensures the quality requirements of the air conditioning parameters, according to UIC 553 OR: 2003 [4]. Although this is high power equipment, it ensures civilized transport.

In the last 30 years, the issue of air conditioning in urban transportation vehicles has been neglected. It has always been considered that air conditioning systems are great energy consumers and that the urban transportation would be better if more vehicles are used. The biggest problems arise in summer and winter, when the transport conditions are terrible, Romania having a continental climate.

Although this is high power equipment, it ensures civilized transport conditions and comes as a hope to encourage more passengers to use modern electric public transportation - trams, light rail, trolleybuses.

A $25 \mathrm{~kW}$ static converter has been assimilated for two axle trolleybuses, with output voltages insulated from the input voltages; a $40 \mathrm{~kW}$ source was assimilated for the three axle trolleybuses.

A type CS12TB source has been assimilated for new trams driven by threephase inverters and asynchronous traction motors with a power of $36 \mathrm{kVA}$; on a tram two of these converters are mounted. Fig. 3 presents the block electrical diagram and fig. 4 an overview of the converter type CS12TB. 


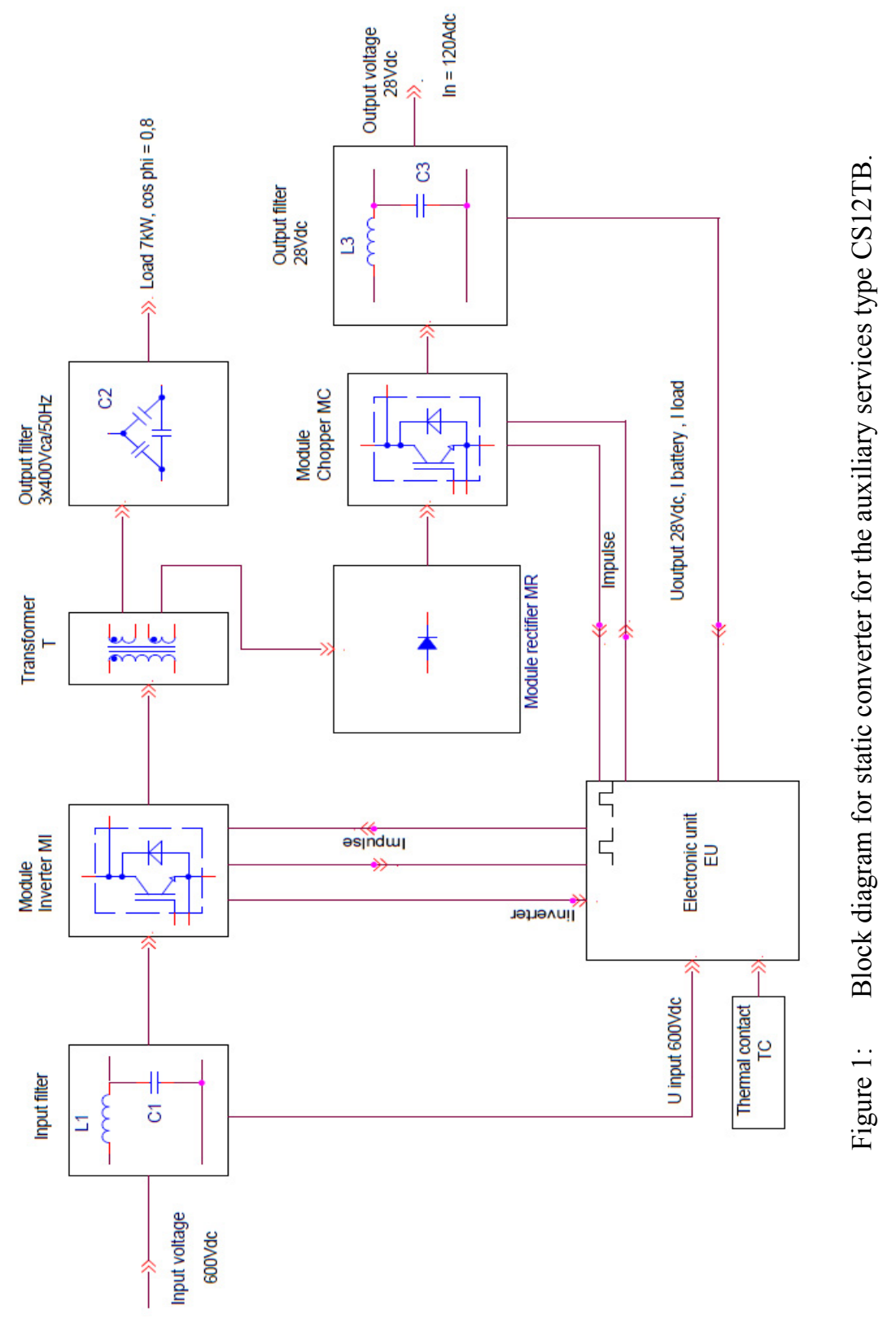




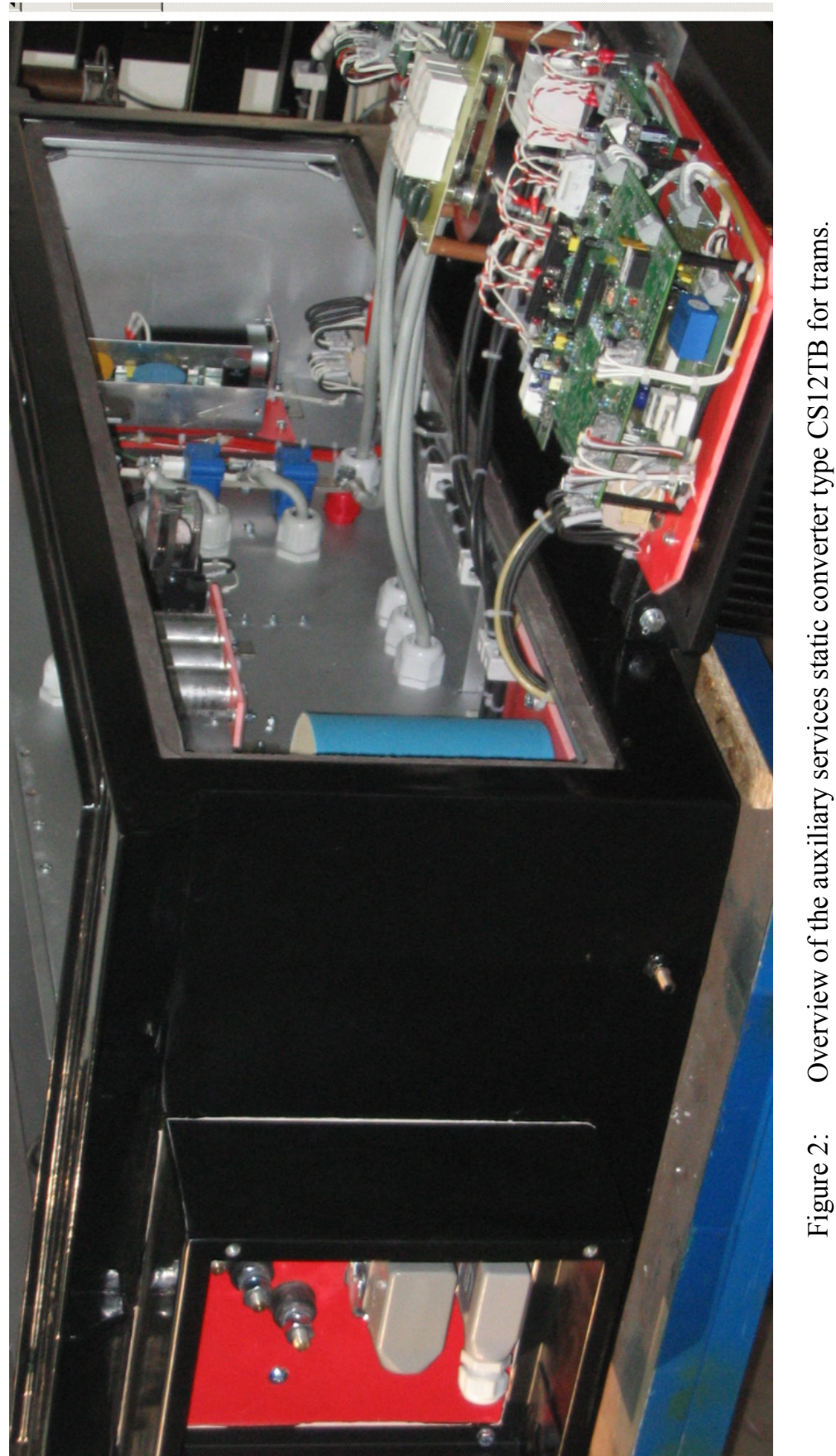




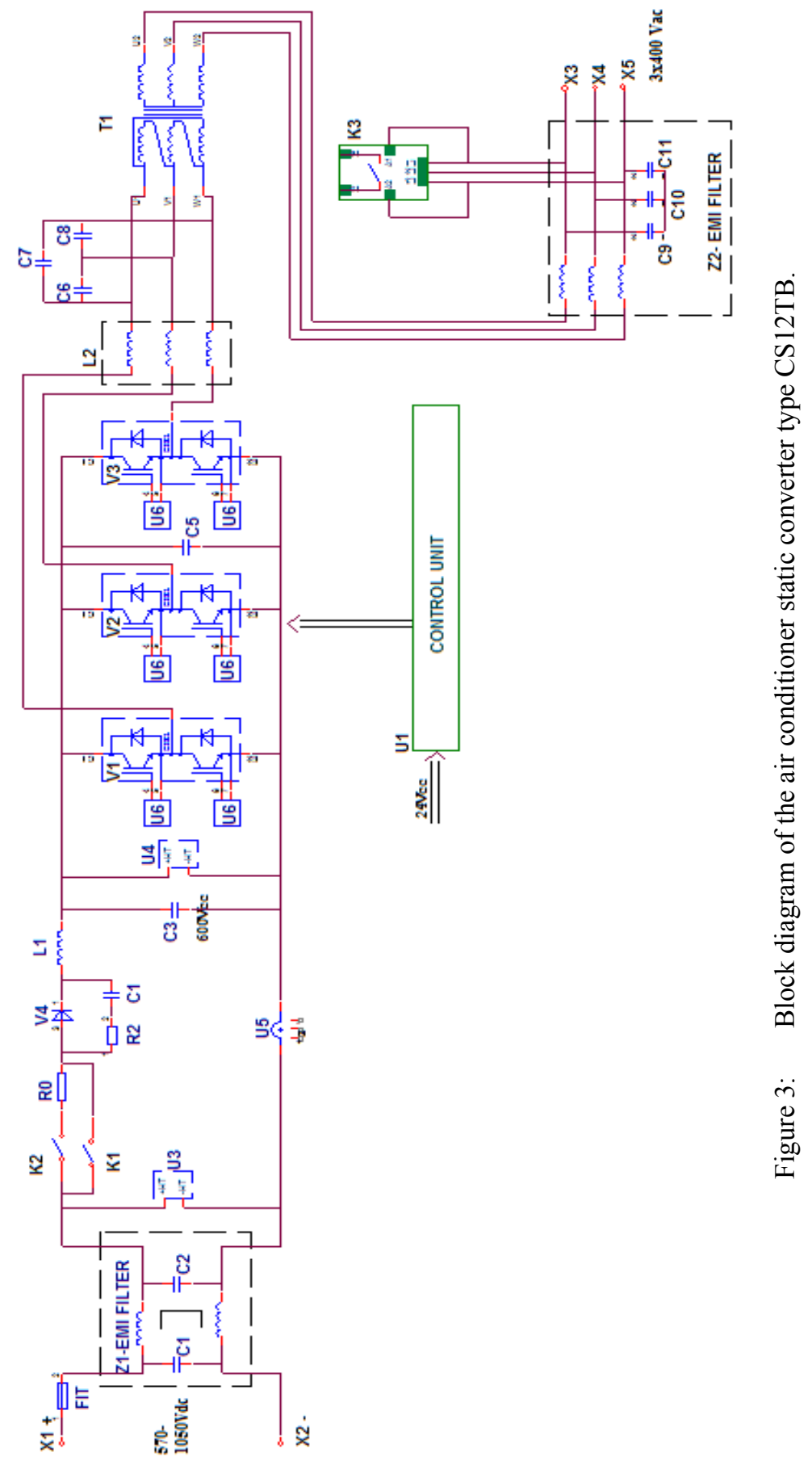




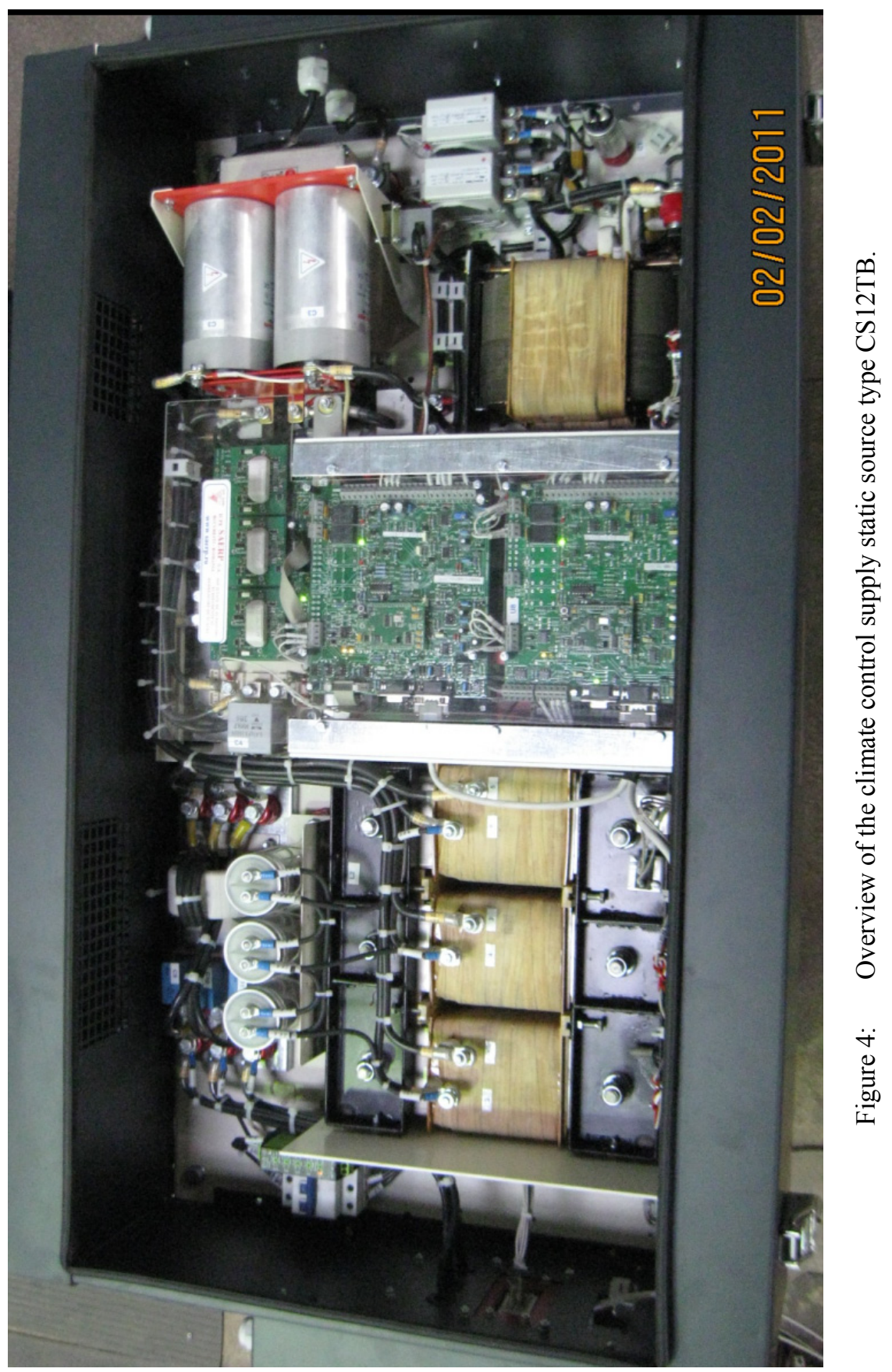




\subsection{Functional characteristics of the static source type CS12TB}

Input parameters:

- line rated voltage

- maximum input current

- control unit supply voltage

\section{Output parameters:}

- three phase nominal voltage

- voltage precision

- nominal frequency

- frequency precision

- nominal phase current

- maximum phase current
: $\quad 350 \ldots 900 \mathrm{Vdc}$

: $100 \mathrm{~A}$;

: $24 \mathrm{Vdc}(+20 \ldots-30 \%)$

\section{Additional measures}

A universal payment system has been implemented in Bucharest to simplify the payment of transport fares for surface and underground urban transportation. This implies using a special pre-pay card that can be recharged and can be used for both surface (ensured by RATB) and underground (ensured by METROREX) transportation.

Urban transportation vehicles will be equipped with systems to assist disabled persons and baby strollers to use the vehicles. For this purpose in the last two years all the new trolleybuses, light rail frames and trams have a low floor. At present, there is one low floor vehicle for every two normal ones.

All the urban transportation vehicles will be equipped with audio and video information systems that will transmit:

- The name of the next station;

- $\quad$ The commuting information;

- $\quad$ The date and the time;

- The GPS position and the map;

- $\quad$ Other necessary information.

\section{Conclusions}

The development of the large cities in Romania, especially of the capital, Bucharest, and the exaggerated increase of the number of cars, mostly used cars from Western Europe, after long time use has contributed to the pollution of these cities and resulted in a horrific urban traffic, particularly during the morning and evening rush hours.

To encourage the population to use public transportation a series of measures have been proposed: 
- The extension of the underground metro network and increasing the number of frames in use; an optimum transport rhythm would be a train every $2-3$ minutes;

- The extension of the light metro network [3], a network that would be off limits to other vehicles such as cars;

- Ensuring that the stations can allow as many urban transport vehicles as possible, including those near metro stations;

- Traffic restrictions for private cars and other small transport vehicles in the city center, to ensure fluent circulation of trams and trolleybuses.

- Encouraging the population to use the electrical urban transportation depends a lot on comfortable transport conditions, especially during summer and winter or harsh weather conditions. For this purpose, air conditioning systems have been mounted on trams, on trolleybuses and on traditional and electric buses.

- Information systems, ergonomic chairs, urban transport fare payment with one single type of rechargeable ticket etc.

- Using passenger and private car owner monitoring and questioning systems to modernize the urban electrical transportation means, considering that these ensure reducing pollution in large cities.

\section{References}

[1] Master Plan for Urban Transport in Bucharest. 15.04.2008, General Counsel of Bucharest.

[2] Hubell J., Wirasinghe S.C., McKendrick N., Morgan D., Mode succession in a public transit corridor, Urban Transport XV -2009, WIT Press.

[3] Străinescu I., Rădulescu V. The Need for Change of the Transport Mode in the Great Cities of Romania. Urban Transport XV -2011, WIT Press.

[4] UIC 553 OR : 2003. Ventilation, chauffage et climatisation des voitures. 